\title{
Effect of Different Levels of Constructivist Scaffolding within E-Content on Undergraduate Students' Mastery of Learning and their Attitudes towards it
}

\author{
Nader Said Shemy \\ Faculty of Education, Arab Open University, Oman. \\ Email:nshemy@aou.edu.om Tel: 0096892803313
}

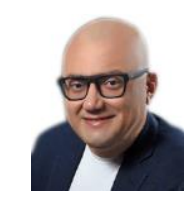

\section{Abstract}

This research investigates the effect of different levels of constructivist scaffolding within e-content on undergraduate students' mastery of learning and their attitudes towards it. The research sample involves three experimental groups, each group having thirty (30) students. The first group (Group 1) studied e-content with simple constructivist scaffolding, the second group (Group 2) studied econtent with intermediate constructivist scaffolding, the third group (Group 3) studied e-content with intensive constructivist scaffolding. The results indicate that the third group of students, who studied design skills with intensive scaffolding, scored higher than the other two groups; they achieved $85 \%$ proficiency. Though the differences are not statistically significant, the students in the other two groups did not achieve the same proficiency percentage $(85 \%)$. The results further reveal that the students in the first and third groups had more positive attitudes than the students in the second group.

Keywords: E-content-based scaffolds, Technology-enhanced learning, E-Learning, E-Content, Constructivist learning scaffolding, Learning for mastery, Undergraduate students.

Citation | Nader Said Shemy (2022). Effect of Different Levels of Constructivist Scaffolding within E-Content on Undergraduate Students' Mastery of Learning and their Attitudes towards it. Journal of Education and e-Learning Research, 9(1): 17-27.

History:

Received: 4 January 2022

Revised: 7 February 9092

Accepted: 21 February

Accepted: 21 February 2022

Licensed: This work is licensed under a Creative Commons

Attribution 3.0 License $(\mathrm{ccc})$

Publisher: Asian Online Journal Publishing Group
Funding: The research leading to these results has received funding from the Research Council (TRC) of the Sultanate of Oman under the Block Funding Program (Grant number: BFP/RGP/ICT/19/283).

Competing Interests: The author declares that there are no conflicts of interests regarding the publication of this paper.

Transparency: The author confirms that the manuscript is an honest, accurate, and transparent account of the study; that no vital features of the study have been omitted; a dhat any discrepacies from the study as plang been omitted; and th explained.

Ethical: This study followed all ethical practices during writing.

Contents

1. Introduction

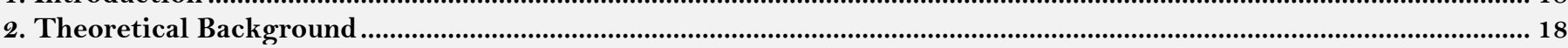

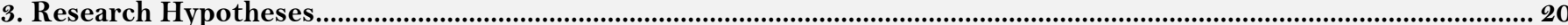

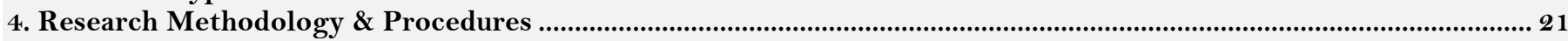

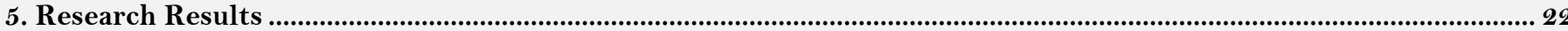

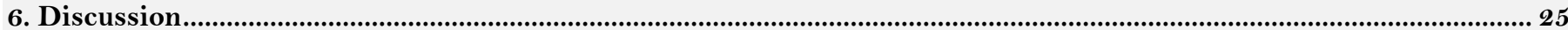

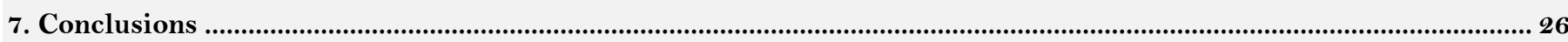

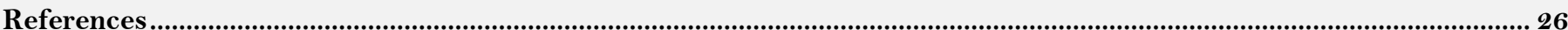




\section{Contribution of this paper to the literature}

This study investigates the value of constructivist learning scaffolding in the provision of interactive e-content to undergraduate students. Moreover, it creates a link between the concepts of scaffolding and mastery of learning, which can lead to an improvement in intended learning outcomes. In addition, the study provides valuable insight into teachers' professional development.

\section{Introduction}

Learners' needs change according to their roles and responsibilities and their interaction with the e-learning environment. In this respect, the constructivist concept of learning scaffolding becomes relevant and essential. It is considered an empirical model of the constructivist school based on the principles behind the theories of cognition and construction. Introducing this concept, Bruner used the term 'scaffolding' to describe the processes in which the novice learner is assisted to accomplish the tasks that he/she would not be able to achieve on his/her own without assistance (Lajoie, 2005). The term has been extended to describe several techniques used to support learners. In other words, assistance is provided by the teacher or the learning environment, whether this is a program or learning unit enhancing the learning process. Scaffolding can help learners accomplish the required task according to their abilities and help them achieve proficiency. Accordingly, scaffolds are paths used to build on prior knowledge to help learners acquire knowledge they do not yet have (Shapiro, 2008). Using these scaffolds within e-content could help learners achieve the proficiency required.

Nevertheless, the levels on which these scaffolds are used differ. They could be primary soft scaffolds, average or rigid complex scaffolds. This research focuses on the effects of different levels of learning scaffolding in e-content on students' learning mastery.

During the researcher's supervision of groups of students taking part in field training in technology-enhanced learning in multiple classrooms, a deficiency in the application of learning design skills was noted. This became apparent through the tasks students completed during the field training sessions in schools. One example of the application of this skill is to create a learning design for a lesson or situation posed by the school's options and circumstances. The researcher found it necessary to go back to the students' results in the course on designing learning situations, which had been taught in the first semester. The researcher found that the students' grades were high compared to their scores in the field training, an observation which was shared by the supervisors of other groups in other schools.

The researcher held sessions with some students to confirm the problem, especially as it had not been long since they had studied the design of learning situations in their first semester. The discussions with the students revealed that the students did not get enough practice with the different steps and stages of learning design and their application in real life, and the focus had been more on the study of the theory. Such skills, however, require practice, continuous evaluation, and assessment. It was found that the time allocated for practice was not enough, and the students did not receive sufficient scaffolding while practicing the design of hypothetical learning situations, which are different from real situations. This could explain the gap between their test results and their ability to apply their knowledge to real life. Indeed, this is what prompted the researcher to take steps to find a practical solution.

One solution to this problem would be to find a tool that ensures continuous assistance and scaffolding. Through a review of previous studies, the researcher has discovered that constructivist learning scaffolding provides continuous assistance and guidelines for what to do in every step while learning and applying knowledge. The researcher further found that web-based e-content is the most suitable method to solve this problem for the following reasons: (1) the possibility of providing scaffolding levels that facilitate assistance, (2) the ready availability of sources and tools, (3) the provision of ample practice time as opposed to the limited practice time in the classroom, and (4) the reduction of the effort required from the teacher and the promotion of independent learning.

However, what is the most appropriate level of scaffolding to provide within e-content to students of technologyenhanced learning in order to master these skills? To what extent do they accept the different levels of scaffolding? This paper aims to address these questions. Thus, the main research question is formulated: What is the effect of different levels of constructivist scaffolding within e-content on undergraduate students' mastery of learning, and what are their attitudes towards it?

\section{Theoretical Background}

\subsection{E-Content}

There are various definitions of e-content, although they all have the same general meaning. According to Khamis, e-content is the collection of topics learners should acquire while learning through specific electronic media. It includes any form of written, audio, or visual information systematically and meaningfully gathered and organized by official educational authorities. E-content is provided for learners through web-based digital educational media and sources to be used in learning to achieve specific educational goals (Khamis, 2015). Al-Ghareeb defines e-content as an information environment that includes electronic scientific sources formulated and produced to help learners practice research skills and gain knowledge electronically through innovative, interactive methods in electronic learning environments. This helps students to achieve learning electronically through the acquisition of behavioral changes that suit the learning objectives (Al-Ghareeb, 2009). Al-Muteiry described e-content as a web-based, interactive, computational learning curriculum involving tools that facilitate communication between learners and instructors. These tools are provided to learners in either synchronous or asynchronous forms using a Course Management System (CMS) (Al- Muteiry, 2008).

The e-content and accessible data applications used to deal with multimedia programs related to e-learning and compatible with SCORM criteria for displaying and transferring e-content are transferred and exchanged. In addition to the educational material in the e-content, there are various electronic services and tools on electronic learning websites for students to practice their interactive learning. These services include related websites, tasks, forums, and discussions that can be accessed through a direct internet connection. These services are used to discuss the content and supply students with the required information to implement and understand direct conversations 
between students, experts, and teaching staff. One of the advantages of employing these elements of e-content is that students can submit their technological and educational contributions to others to revise and build on, while developing skills through this exchange of information. As a result, students have the chance to review and follow up on their skills and ideas. They are also provided with feedback that makes their learning more effective (AlGhareeb, 2009). Scaffolding and guiding are two main characteristics of e-content because it is meant for independent study. It should include the different methods of scaffolding, assisting, and guiding the learner. This methodology helps learners to absorb the e-content with little or no assistance.

\subsection{Constructivist Scaffolding Within E-Content}

Constructivist scaffolding in the e-learning environment has been a point of great interest in technologyenhanced learning due to its potential for enhancing efficacy. The application of structural scaffolds in computational, technology-enhanced learning environments and web-based, hypothetical learning environments has changed the concept of constructivist scaffolding; it is no longer based on direct interaction between learners and instructors. It has also led to the increased possibility of helping learners acquire knowledge in the Zone of Proximal Development (ZPD). Scaffolding includes alternative ways of offering assistance that increase the learner's responsibility and decrease the instructor's direct interference. Structural scaffolds have become tools, sources, and programs that include various forms of scaffolding, assistance, and other facilities (Puntambekar \& Hubscher, 2005). According to Azevedo and others, structural scaffolds are strategies and guidelines that can help learners organize their comprehension of complicated topics in interactive, multimedia-based learning environments. Such topics cannot be acquired if the learner depends only on himself/herself to learn them (Azevedo, Cromely, Leslie, Seibert, \& Tron, 2003; Resier, 2002). Oliver illustrates that the first design element of an e-learning environment is learning scaffolds. These environments require scaffolds to be designed and incorporated within the learning process. Scaffolding is a necessary tool to guide and assist learners through the e-content to allow them to build their knowledge independently. Additionally, scaffolding specifies the place where the learner receives assistance in the learning process when performing a task to increase their knowledge (Oliver \& Herrington, 2001). Simons emphasizes that interactive learning based on structural scaffolding in the e-learning environment is a practical learning approach. He also notes that structural scaffolds are the focal point of interest in any electronic learning medium. It is essential to apply scaffolding techniques within the interactive scope, to help learners achieve their learning goals (Simons \& Ertmer, 2006).

\subsection{Scaffolding Levels}

The support and assistance provided in multimedia computer software and e-learning environments can be categorized in three levels: brief (simple), intermediate, and detailed (intensive) (Alvarez \& Cuesta, 2012; Dolaty, 2011; Donovan \& Smolkin, 2011; Schutt, 2003; Sofi, 2006; Zydney, 2003). Accordingly, in this study, the researcher identifies three levels of progression of constructivist scaffolding within web-based e-content, namely the simple level, the intermediate level, and the intensive level; the quantity and type of scaffolding offered depends on the characteristics of the learners, the task, and the learning environment. Each level of constructivist scaffolding is outlined below.

\subsubsection{Simple Learning Scaffolding}

This level of scaffolding offers the minimum amount of support and assistance that must be available in the econtent, which cannot be dispensed with. In this level, the learner is provided with assistance, directions, instructions, and indirect hints in every step of the e-content, as follows:

1. It should be provided mainly at the beginning of the e-content.

2. It provides the learner with instructions and directions to help him interact with and control the e-content, without the need for an external guide.

3. It allows the learner to call for procedural support by pressing the help button.

4. The e-content should provide simple and brief learning scaffolding within the instructional tasks.

5. The e-content provides the support the learner needs for the instructional tasks in a simple and brief form that helps him solve any problem.

6. It provides the learner with different types of verbal hints and directions to help him enhance his performance.

7. The support encourages the learner to carry out the instructional activities by making him responsible.

\subsubsection{Intermediate Learning Scaffolding}

In addition to the support provided by simple learning scaffolding, intermediate scaffolding includes assistance, directions, examples, questions, and hints, as follows:

1. The e-content should provide intermediate learning support within the instructional tasks that suits the characteristics of the learners.

2. It focuses on complex and difficult skills based on basic concepts, without going into detail and excluding what is unnecessary.

3. It provides additional examples, hints, explanations of terms, or reminders.

4. It provides the learner with different forms of verbal, audible, static, and animated graphic instructions to help him perform difficult educational tasks on his own.

5. The e-content asks the learner questions that encourage him to think and reflect and to choose from alternatives to solve problems.

6. It provides advice and guidance through modeling, presentations, and feedback, and simplifies only the required orders.

\subsubsection{Intensive Learning Scaffolding}

In addition to the support provided by intermediate learning scaffolding, intensive scaffolding helps the learner focus on important and complex topics and concepts. It helps the learner organize and structure information to 
develop a clear understanding of the concepts. This level of scaffolding provides the learner with the assistance he needs to perform tasks by providing him with hints, instructions, more examples, leading questions, and an expert model, as follows:

1. The e-content provides the learner with scaffolding that simplifies complex and difficult tasks, clarifies the necessary characteristics, focuses on the basic concepts, and provides an accurate explanation and clarification of the required skill.

2. It provides the learner with different types of support in the form of educational organization to help the learner organize information, clarify ideas, compare concepts, and draw conclusions.

3. It equips the e-content with intensive learning support designed to allow all instructional tasks and skills to be presented in an organized manner using mechanisms that provide learners with introductory organization, graphic organizers, segmentation of operations and functions, hints, examples, tables and figures, an expert model, etc.

4. It provides the learner with various forms of verbal, audible, fixed, and animated hints and directions to help him perform difficult instructional tasks on his own.

5. The presentation of educational models should be accompanied by explanatory phrases so that the learner can apply these educational design models to the design of new learning situations.

6. It should be presented in the form of additional examples, with an accurate explanation or reminder of the terms.

7. It provides planning support that helps the learner define his goals and record his thoughts, observations, and questions.

8. It provides ideal solution paths and models correct responses to help the learner achieve proficiency.

9. It provides learning support for each part of the content, exercise, and activity.

10. The scaffolding should support the different aspects of learning and not be limited to one specific task.

11. It provides the learner with a performance report to help him monitor his progress and evaluate his performance.

Many studies have focused on the learning scaffolding provided in e-learning environments and its effectiveness. Chang, Tarng, and Shin (2009) revealed the effectiveness of scaffolding in a web-based adaptive learning system, and their results showed a significant improvement for students. Another study, Afifi (2010), employed scaffolding as a design variable to better manage educational projects for students online. Gad and Al-Maradini (2010) examined the effects of the interaction between different types of scaffolding within an e-book on students' achievement and learning efficiency; they discovered the value of designing learning scaffolding within online learning environments. Abdel Kafi (2009) aimed to discover the effects of certain aspects of learning scaffolding in multimedia programs on the achievement and development of metacognitive skills among technology students. Al-Salami (2008) investigated the effect of the interaction between two types of fixed and flexible learning scaffolding (tape/drop-down list) and the learning style, achievement, and learning time of female students designing multimedia programs. Shahinaz (2007) confirmed that the use of informational and procedural learning scaffolding led to a supportive and encouraging learning environment that enabled female students to construct their learning according to their own needs and abilities. Around the same time, another study, Sofi (2006), aimed to identify the impact of different levels of guidance in multimedia programs on the development of cognitive and behavioral aspects of students; the study recommended the use of different forms of guidance to activate students' acquisition of knowledge. Finally, Stewart, MacIntyre, Galea, and Steel (2007) confirmed the benefits of educational support in e-learning environments and the amount of assistance and feedback provided by such scaffolding to the learner in the e-learning environment.

Reviewing the above studies and other research papers related to the design and construction of learning scaffolding in e-learning environments, it was found that there is full agreement on the importance of learning scaffolding and the need to design it for these environments, as well as the fact that scaffolding has become an essential element in the educational design process. E-learning environments can facilitate the learning process and provide learners with hints and instructions that encourage them and remind them of the steps to be taken. Elearning environments with learning support provide the learner with additional assistance that is greater than that provided by programs without support; the scaffolding becomes an inseparable part, allowing the learner to achieve the tasks in a more profound and enthusiastic way. This leads to students reaching the point of mastery in learning.

\subsection{Learning for Mastery}

Block and Burns define 'learning for mastery' as a set of ideas, learning practices, procedures, and assessments that target the improvement of the learning offered to students so that all or most of them attain proficiency in the learning material (Block \& Burns, 1976). Learning for mastery requires small learning units that are successively organized with specific goals, multiple performance levels, initial group teaching, cumulative formation tests, and individual or group feedback (Tawfiq \& Al-Heela, 1998).

There is a group of factors that could assist in achieving learning mastery. These include clearly defining learning objectives, focusing on the learner's active responses, maintaining a positive atmosphere of learning and its results, organizing the content well, encouraging learners' motivation, considering individual differences, coordinating the learning objective with the assessment, providing continuous and frequent assessment, and providing feedback and enhancement (Riad, 2002). Reviewing these factors, it has been found that the different forms of scaffolding can contribute to each. Scaffolding clarifies goals and helps students to interact with the e-content, thus contributing to a positive learning atmosphere. It also illustrates how the content can be organized through maps. Scaffolding plays a significant role in facilitating learning that takes individual differences into account. In sum, constructivist learning scaffolding of e-content can help students attain learning mastery.

\section{Research Hypotheses}

Based on the reviewed literature and the results of previous studies, along with the researcher's field experience in instructional technology and the design and production of interactive multimedia, the following hypotheses are proposed, the validity of which will be assessed and verified through subsequent research procedures. 
1. There are statistical differences at the level 0.05 in the post-skill achievement between the average grades of Group 1 students who studied e-content with primary structural scaffolding, Group 2 who studied e-content with average structural scaffolding, and Group 3 who studied e-content with complex structural scaffolding. These differences are due to the level of scaffolding provided to learners.

2. There are statistical differences at the level 0.05 in the proficiency percentage $(85 \%)$ of the three groups between the average grades of Group 1 students who studied e-content with primary structural scaffolding, Group 2 who studied e-content with average structural scaffolding, and Group 3 who studied e-content with complex structural scaffolding. These differences are due to the impact of the level of scaffolding provided to learners.

3. There are statistical differences at the level 0.05 in post-measurement between the average grades of Group 1 students who studied e-content with primary structural scaffolding, Group 2 who studied e-content with average structural scaffolding, and Group 3 who studied e-content with complex structural scaffolding. These differences are due to the level of scaffolding provided to learners.

\section{Research Methodology \& Procedures \\ 4.1. Methodology}

In this research study, a quasi-experimental approach was applied to test the effect of different levels of constructivist scaffolding within e-content on undergraduate students' mastery of learning, as well as their attitudes towards it.

\subsection{Research Procedures}

First: The researcher prepared a list of instructional design skills required by instructional technology students; the list includes a set of basic skills ( 7 skills), and each skill involves a set of sub-skills ( 40 skills). The basic skills are learning design basics skills, learning design phases essential skills, analysis phase skills, design phase skills, development phase skills, application and final assessment phase skills, and employment and monitoring phase skills. The researcher presented the list to four reviewers in the field of instructional technology and instructional design; the required modifications were implemented, and the list of skills was finalized.

Second: E-content that included the instructional design skills required by instructional technology students was designed and developed to include three levels of support (simple, intermediate, and intensive). Using the list of skills, the researcher selected the e-content for learning design skills required by students, enhanced by one of three levels of scaffolding. Each level was presented with a different subject, and the students used in the research sample were recorded. The sample students studied the e-content through the e-learning environment Moodle. The researcher selected the Moodle environment because it is an open-source Course Management System, it is user-friendly, and it offers the tools necessary to implement the research. It can also be managed in Arabic. The participating students also used Moodle to study some of the electronic subjects at Al Fayoum University. Table 1 illustrates the differences between the three subjects that represent each scaffolding level (simple, intermediate, and intensive).

Table 1. Scaffolding levels, types \& patterns used in each level.

\begin{tabular}{|c|c|c|}
\hline Scaffold level & Scaffold type & Scaffold styles \\
\hline $\begin{array}{l}\text { E-content with simple } \\
\text { scaffolding }\end{array}$ & $\begin{array}{l}\text { - } \quad \text { Procedural scaffolds (goals-instructions-content map) } \\
\text { - } \quad \text { Conceptual scaffolds (terms-tables) }\end{array}$ & Flexible \\
\hline $\begin{array}{l}\text { E-content with intermediate } \\
\text { scaffolding }\end{array}$ & $\begin{array}{ll}\text { - } & \text { Procedural scaffolds (goals-instructions-content map) } \\
\text { - } & \text { Conceptual scaffolds (terms-fixed/animated illustrations-tables) } \\
\text { - } & \text { Advice scaffolds (hints-examples-questions) } \\
\end{array}$ & Flexible \\
\hline $\begin{array}{l}\text { E-content with intensive } \\
\text { scaffolding }\end{array}$ & $\begin{array}{ll}\text { - } & \text { Procedural scaffolds (goals-instructions-content map) } \\
\text { - } & \text { Conceptual scaffolds (terms-fixed/animated illustrations-tables) } \\
\text { - } & \text { Expice scaffolds (hints-examples-questions) + additional examples } \\
\text { skill performance or the product) }\end{array}$ & Flexible \\
\hline
\end{tabular}

\subsection{Research Tools}

For the purposes of the current research, the researcher used two main research tools.

\subsubsection{Observation Card for Instructional Design Skills}

Based on the aims of the study, the learning objectives, and the skills that the students should acquire, the researcher designed a card to measure the skills. The card aims to reveal the performance of fourth-year students on a technology-enhanced course in accomplishing the required tasks in the web-based e-content using the structural scaffolding to develop their learning design skills. Then, the researcher created an instruction page for the observation card, ensuring that the precision and clarity of the instructions were sufficient for any observer to use it accurately and efficiently. The wording of the observation card was made to serve the learning goal of the e-content. It involves five (5) primary skills and twenty-five (25) sub-skills. The card includes phrases that describe the actions the learner is required to perform step-by-step during the tasks and that encompass the different performance levels of the skill. The researcher also specified the method of recording the observation using the quantitative method of grading. There are three options next to each phrase reflecting the learner's achievement level (excellent-averageweak).

Then, the researcher tested the card to improve it. This was done by carrying out tests to confirm the validity and reliability of the information. After confirming the validity of the card, the researcher made amendments according to experts' opinions. They confirmed the validity of the observation card, changing only a few words and some punctuation marks and deleting some repeated steps. After that, the final form of the card was applied to a focus group for reliability calculation. In calculating the reliability factor of the observation card, the researcher draws on the method of variance analysis, which means analyzing the students' different grades. The reliability factor of the 
observation card is thus calculated using Kuder Richardson equation number 21 (KR-21). The results indicated that the observation card is highly reliable. After confirming the validity and reliability of the observation card, it was judged valid for use in assessing the students' performance in learning design skills.

\subsubsection{Attitude Scale for the Levels of Constructivist Learning Scaffolding}

The researcher created a measure for the attitudes of learners on technology-enhanced courses towards the levels of structural scaffolding; this aimed to measure the attitudes of fourth-year students towards the structural scaffolding levels (basic-average-complex) to check how much they are influenced, and whether they have a positive or negative attitude towards using them. The researcher designed the wording of the attitude measure based on the advantages of using it and the criticisms of constructivist scaffolding in e-content. Twenty items reflect the objectives of the measure. The researcher carried out all the required tests to control its quality. It was brought to four (4) referees and subjected to several tests to confirm its validity and reliability.

\subsection{Research Sample}

The original community of research includes the final-year students of the Bachelor of Instructional Technology in Egypt, whose ages range from 21 to 22. In general, they embody the characteristics of speedy mental development and growth of imagination from illusion to realism, which tends towards innovation and creativity. In addition, the research sample consisted of 90 students selected from the education faculty at Cairo University, divided into three experimental groups, each of which included 30 students. The researcher found that this number was suitable as a sample for the current study. In addition, the researcher selected the research sample using the regular randomized sampling method.

\section{Research Results}

\subsection{Testing the $1^{\text {st }}$ Hypothesis}

The first hypothesis states, "There are statistical differences at the level 0.05 in the post-skill achievement between the average grades of Group 1 students who studied e-content with primary structural scaffolding, Group 2 who studied e-content with average structural scaffolding, and Group 3 who studied e-content with complex structural scaffolding. These differences are due to the impact of the level of scaffolding provided to learners." To test or verify the validity of this hypothesis, the researcher applied the ANOVA test to the significances of the differences between the average grades of the three experimental groups obtained from the application of the skills observation card. Table 2 illustrates the results of the ANOVA test.

Table 2. The ANOVA test results of the significances of the differences between the average grades of the three experimental groups obtained from the application of the skills observation card.

\begin{tabular}{l|c|c|c|c|c|c}
\hline Statement & Total of squares & $\begin{array}{c}\text { Degrees of } \\
\text { freedom }\end{array}$ & $\begin{array}{c}\text { Average } \\
\text { squares }\end{array}$ & Value F & Significance & Decision \\
\hline Among the groups & 795,27 & 2 & 397.63 & 14.02 & \multirow{2}{*}{0.01} & \multirow{2}{*}{$\begin{array}{c}\text { Hypothesis } \\
\text { accepted }\end{array}$} \\
\cline { 1 - 4 } In the groups & 2467,63 & 87 & 82.63 & & & \\
\hline
\end{tabular}

This table illustrates that the Value $\mathrm{F}$ is statistically significant regarding the measured skill achievement. This indicates differences with statistical significance between the average grades of the students in the three experimental groups during the application of the skill observation card.

To verify the differences and conduct multiple subsequent comparisons to specify the differences between the averages of the three experimental groups, the researcher used the Scheffe test. Table 3 illustrates the results of the Scheffe test.

Table 3. The results of the Scheffe test on the average grades of the students in the three experimental groups on the skill achievement test.

\begin{tabular}{l|c|c|c|c}
\hline Groups & Average & $\begin{array}{c}\text { Group 1 Simple } \\
\text { scaffolding }\end{array}$ & $\begin{array}{c}\text { Group 2 } \\
\text { Intermediate } \\
\text { scaffolding }\end{array}$ & $\begin{array}{c}\text { Group 3 } \\
\text { Intensive } \\
\text { scaffolding }\end{array}$ \\
\hline Group 1. Simple scaffolding & 35.80 & - & 3.23 & 7.27 \\
\hline Group 2. Intermediate scaffolding & 39.03 & - & - & 4.03 \\
\hline Group 3. Intensive scaffolding & 43.07 & - & - & 43.07 \\
\hline
\end{tabular}

The table shows no difference between the average grades of Group 1, who studied e-content with basic scaffolding, and Group 2, who studied e-content with intermediate scaffolding. There are, however, differences between the average grades of Group 1, who studied e-content with basic scaffolding, and Group 3, who studied econtent with complex scaffolding. This result is in favor of Group 3. The difference between the average grades of Group 2, who studied e-content with average scaffolding, and Group 3, who studied content with complex scaffolding, is also in favor of Group 3. The researcher attributes the excellence of Group 3 students' learning design skills to the fact that the complex level of scaffolding was the richest in examples and questions compared to the other two levels, the intermediate and the basic. The intensive level also included the expert model scaffolding that provided a ready-made model for every stage in the learning design. It included all the steps and skills and was perfectly implemented by the students. This had a considerable impact on clarifying and explaining some complicated skills to the Group 3 students, which is reflected in the statistically significant differences in their average grades in skill achievement compared to the other two groups.

\subsection{Testing the $2^{\text {nd }}$ Hypothesis}

The second hypothesis states, "There are statistical differences at the level 0.05 in the post-skill achievement between the average grades of Group 1 students who studied the e-content with primary structural scaffolding, Group 2 who studied e-content with average structural scaffolding, and Group 3 who studied e-content with complex 
structural scaffolding. These differences are due to the impact of the level of scaffolding provided to learners." To test or verify the validity of this hypothesis, a T-test is applied to find the significance of the difference between the average grades of students in the three groups under study in the subsequent comparison with the proficiency grade $85 \%$. Table 4 illustrates the results of the T-test.

Table 4. The T-test for the significance of the difference between the average grades of students in the three groups under study in the subsequent comparison with the proficiency grade $85 \%$.

\begin{tabular}{l|c|c|c|c|c|c|c}
\hline Type applied & Groups & MD & STDV & $\begin{array}{c}\text { T-test } \\
\text { Value }\end{array}$ & $\begin{array}{c}\text { Value } \\
\text { F }\end{array}$ & Significance & Decision \\
\hline Subsequent & $\mathrm{G}(1)$ & 35.80 & 5.359 & 6.848 & 29 & 0.000 & Indicative \\
\hline \multirow{2}{*}{ Proficiency 85\% 42.5 grades } & $\mathrm{G}(2)$ & 39.03 & 5.455 & 3.481 & 29 & 0.002 & Indicative \\
\cline { 2 - 8 } & $\mathrm{G}(3)$ & 43.07 & 5.159 & 0.602 & 29 & 0.567 & Non-Indicative \\
\hline
\end{tabular}

Table 4 reveals the differences between the average grades of Group 1, who studied with primary scaffolding, and the proficiency level of $85 \%$, which would indicate mastery. Accordingly, Group 1, who studied e-content with primary scaffolding, did not achieve mastery. The table also indicates the differences between the average grades of Group 2, who studied the e-content with average scaffolding, and the proficiency level of $85 \%$, which would indicate mastery. Accordingly, it can be said that Group 2, who studied e-content with average scaffolding, did not achieve mastery. The table shows no difference between the average grades of Group 3, who studied with complex scaffolding, and the proficiency level of $85 \%$. Accordingly, it can be said that Group 3, who studied e-content with complex scaffolding, achieved mastery. However, the difference between the average grades of Group 3 and the proficiency level of $85 \%$ cannot be promoted to the level of statistical significance. The researcher attributes the mastery of Group 3 to the fact that the complex level of scaffolding was the richest in examples and questions compared to the other two levels, the intermediate and basic. The intensive scaffolding level also included expert model scaffolding, which had a considerable impact on clarifying some complicated skills for Group 3 students.

\subsection{Testing the $3^{\text {rd }}$ Hypothesis}

The third hypothesis states, "There are statistical differences at the level 0.05 in post-measurement between the average grades of Group 1 students who studied e-content with primary structural scaffolding, Group 2 who studied e-content with average structural scaffolding, and Group 3 who studied e-content with complex structural scaffolding. These differences are due to the impact of the level of scaffolding provided to learners." To test or verify the validity of this hypothesis, the researcher applied the ANOVA test. Table 5 shows the results of the ANOVA test to find the significance of the difference between the average grades of students in the three groups under study in the subsequent application of the attitude scale.

Table 5. The ANOVA test results to find the significance of the difference between the average grades of students in the three groups under study in the subsequent application of the attitude curve.

\begin{tabular}{|c|c|c|c|c|c|c|}
\hline Statement & Total of squares & Degrees of freedom & Average squares & Value F & Significance & Decision \\
\hline Among the groups & 170,96 & 2 & 85.48 & \multirow{3}{*}{7.32} & \multirow{3}{*}{0.01} & \multirow{3}{*}{$\begin{array}{l}\text { Hypothesis } \\
\text { accepted }\end{array}$} \\
\hline In the groups & 1015,53 & 87 & 11.67 & & & \\
\hline Total & 1186,49 & 89 & & & & \\
\hline
\end{tabular}

Table 5 illustrates that the value $\mathrm{F}$ is statistically significant regarding the subsequent attitude scale. This indicates statistically significant differences between the average grades of the students in each of the three experimental groups in the subsequent attitude scale.

To verify the differences and conduct multiple comparisons to specify the differences between the averages of the three experimental groups, the researcher used the Scheffe test. The following table illustrates the results of the Scheffe test.

Table 6. The results of the Scheffe test between the students' average grades in the three experimental groups and the subsequent application of the attitude scale.

\begin{tabular}{l|c|c|c|c}
\hline Groups & Average & $\begin{array}{c}\text { Group (1) Simple } \\
\text { scaffolding }\end{array}$ & $\begin{array}{c}\text { Group (2) Intermediate } \\
\text { scaffolding }\end{array}$ & $\begin{array}{c}\text { Group (3) Intensive } \\
\text { scaffolding }\end{array}$ \\
\hline Group (1) Simple scaffolding & 89.80 & - & 3.03 & 0.23 \\
\hline Group (2) Intermediate scaffolding & 86.77 & - & - & 2.80 \\
\hline Group (3) Intensive scaffolding & 89.57 & - & - & - \\
\hline
\end{tabular}

Table 6 demonstrates that there are differences between the average grades of Group 1, who studied e-content with basic scaffolding, and Group 2, who studied e-content with average scaffolding, in favor of Group 1 . There are no differences between the average grades of Group 1, who studied e-content with primary scaffolding, and Group 3 , who studied e-content with complex scaffolding. There are differences between the average grades of Group 2 , who studied e-content with average scaffolding, and Group 3, who studied e-content with complex scaffolding, in favor of Group 3.

The following screens illustrate the e-content produced considering the objectives of the current research paper.

Figure 1 shows the interactive e-content that must include tools for self-assessment, in which each learner answers the assessment's questions and receives immediate and direct feedback. This feedback will help him to evaluate his learning performance and prepare him for further learning.

Figure 2 shows that the interactive e-content must also include a set of tools to help the learner interact with the content, with which the learner can print the content, change the text color and size, and add comments on the content itself. Also, they allow the learner to ask for help at any time while learning the content. 


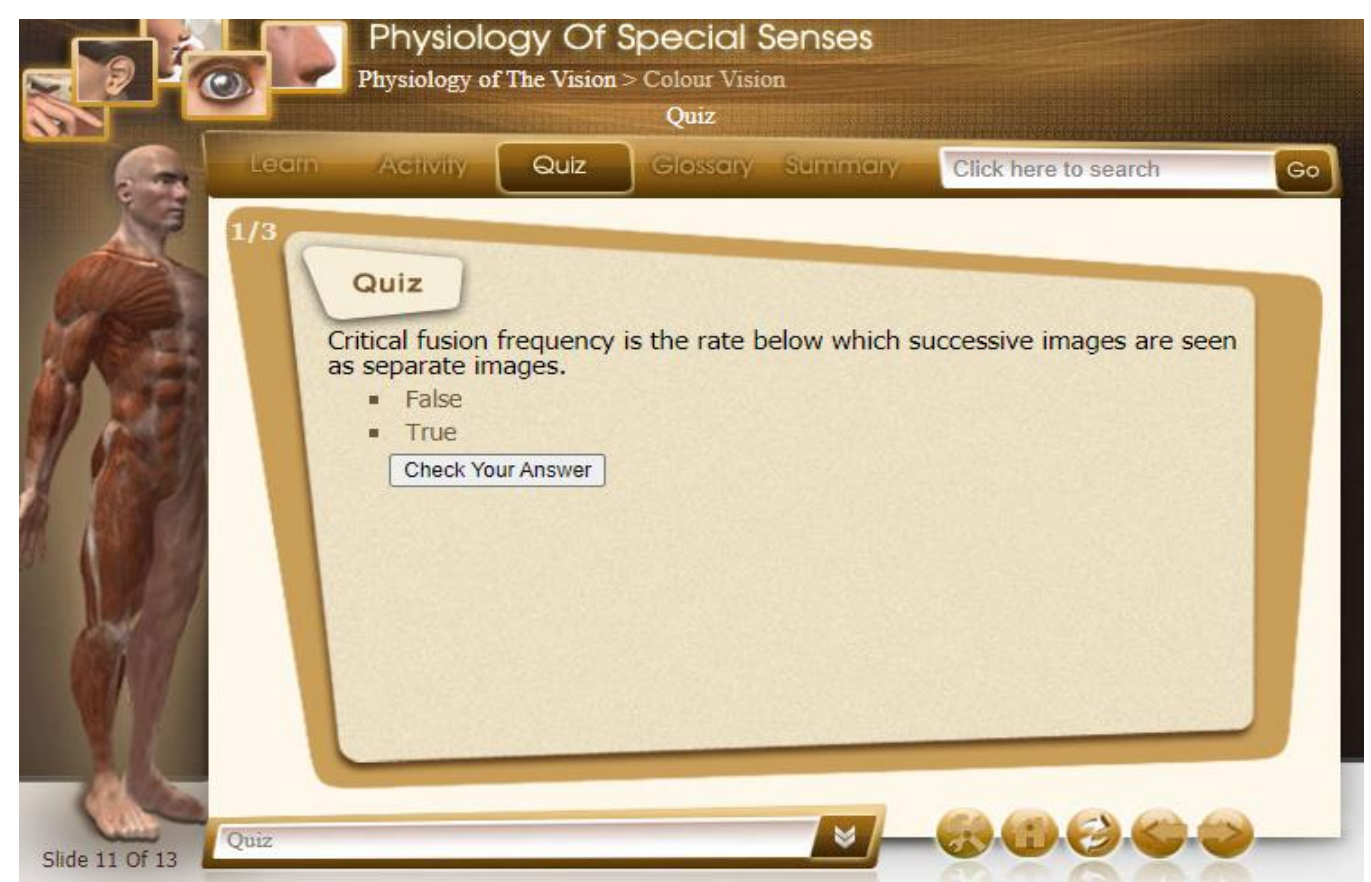

Figure 1. Self-assessment tools in the interactive e-content based on educational scaffolding.

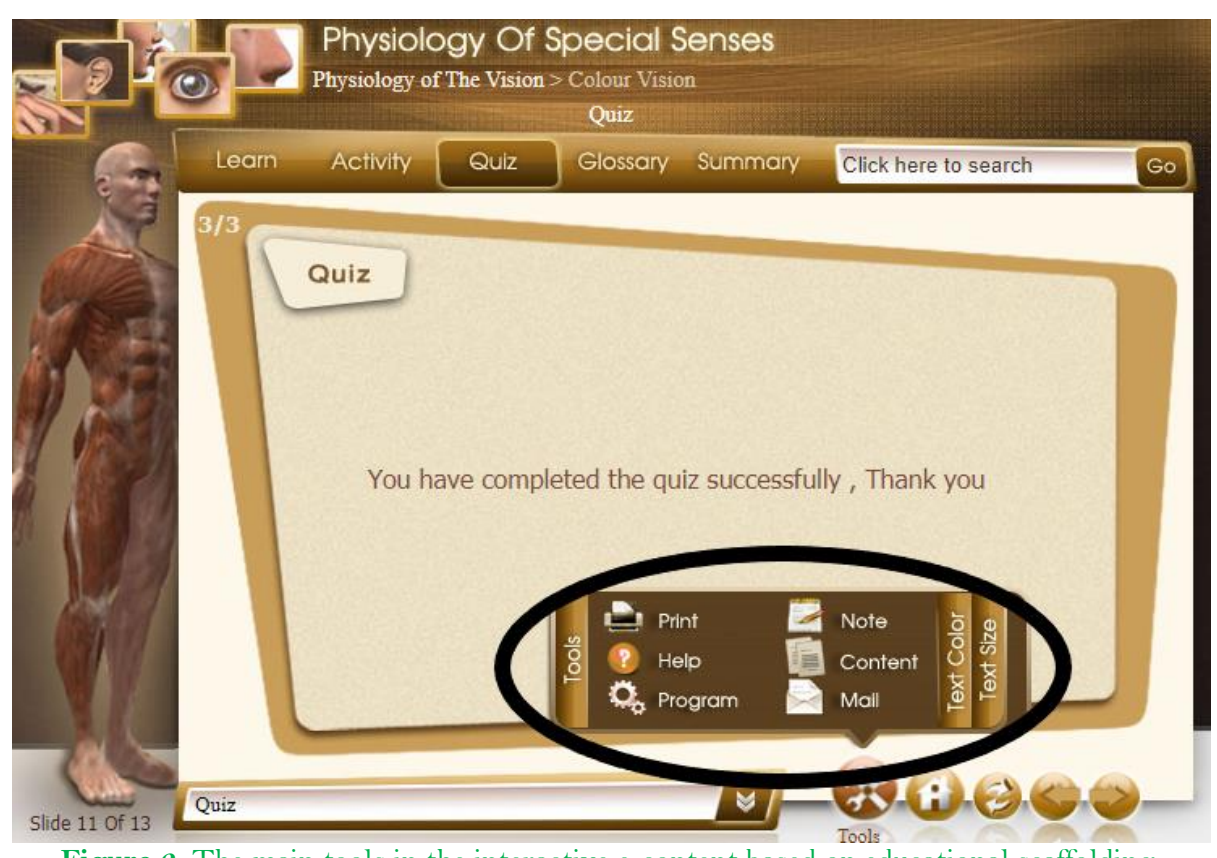

Figure 2. The main tools in the interactive e-content based on educational scaffolding:

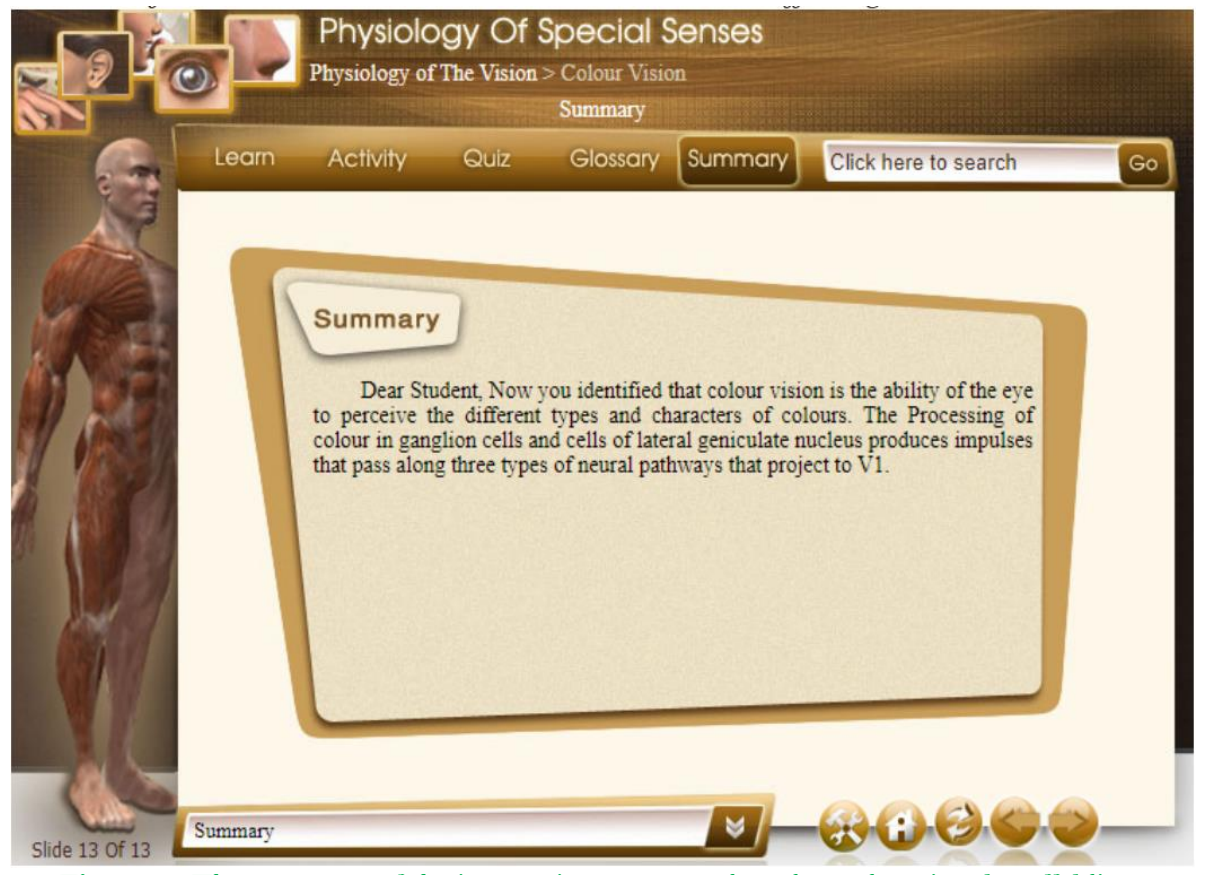

Figure 3. The summary of the interactive e-content based on educational scaffolding.

Figure 3 shows a summary of the content of each learning object, which is one of the important and necessary factors to complete the learners' learning, as it grants the learner an overview of the basic concepts and skills that were presented in the content, which will contribute to the consolidation of the information in the learner's mind. 

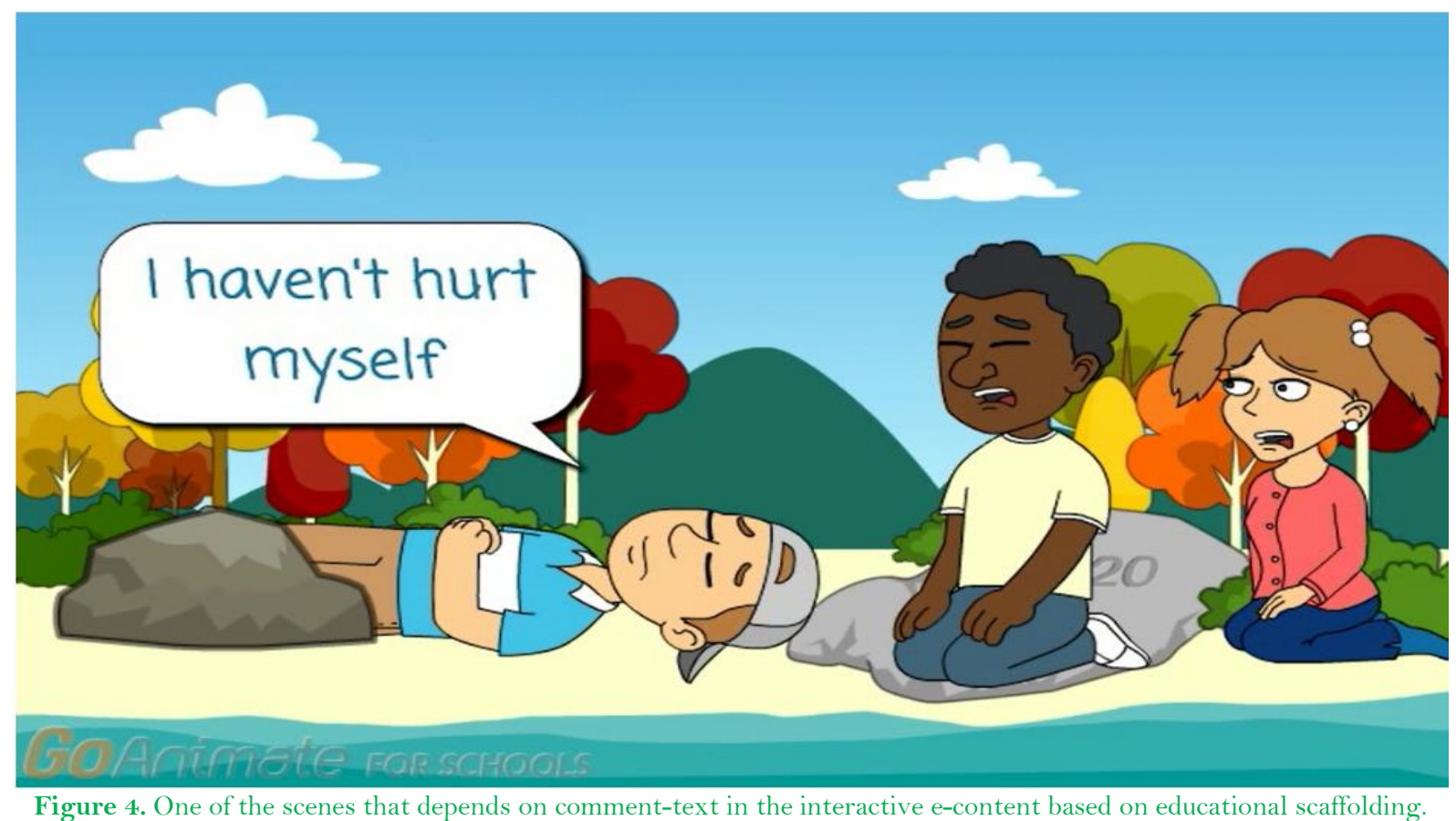

Figure 4 displays one of the forms of presenting representative scenes through the digital storytelling strategy, which relies mainly on a written text dialogue and may in some cases be accompanied by audio narration.

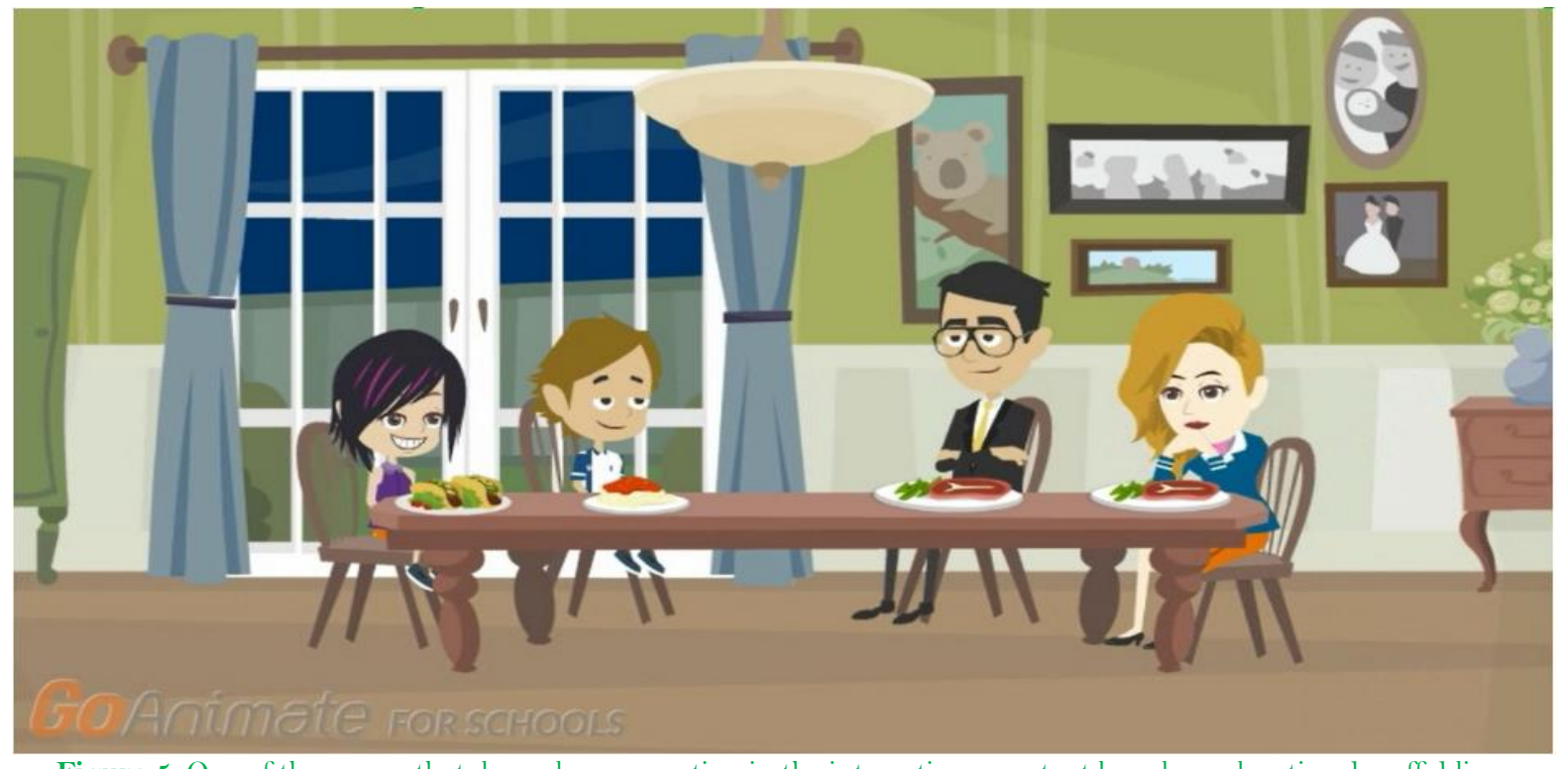

Figure 5. One of the scenes that depends on narration in the interactive e-content based on educational scaffolding.

Figure 5 represents the interactive e-content based on the digital storytelling strategy, but using only audio narration, in addition to the appropriate visual and sound effects.

\section{Discussion}

In traditional education, constructivist scaffolding is essential to help students reach a level of mastery in their learning. In the case of remote and not traditional education, this is all the more important. So, having reviewed the previous research, the researcher confirmed that structural scaffolding with its various methods would be the optimal and most effective solution during the period of COVID-19 restrictions, in which students needed support while having to rely on themselves to acquire and master knowledge and skills. Although the undergraduate-level students who were the subject of this study have admirable characteristics, they have greatly benefited from the constructivist scaffolding of the offered content to reach achieve in-depth learning of the targeted educational concepts. The researcher believes that the intensive pattern of structural scaffolding is the most suitable for the specific characteristics of these students, and the results of the current study confirm this.

Many previous studies confirm the validity of the current results, especially regarding the added value of intensive educational scaffolding (Hou \& Keng, 2021). Integrating educational board games and augmented reality (AR) can help provide extensive cognitive scaffolding for learners. Hou and Keng (2021) proposed a dual-scaffolding framework that integrated peer-scaffolding and cognitive scaffolding in an AR educational board game. The results revealed a positive correlation between learners' flow and acceptance. These learners' behavioral patterns also showed that both peer-scaffolding and cognitive scaffolding facilitated their problem-solving process. Moreover, the study found that high collective flow groups had more reflection and analysis behaviors than low collective flow groups in game-based learning. This is confirmed by Kim, Belland, and Axelrod (2018), who suggested learner-centered scaffolding systems (LSS) to improve K-12 students' perception of optimal challenge by addressing their learning issues in Project-Based Learning (PBL). LSS enhances students' experiences of autonomy and mastery by providing multiple types of scaffolding according to students' different needs and difficulties in PBL. Students can control the nature and frequency of scaffolding according to their needs and abilities, which helps to improve their self-directed learning skills. On the other hand, there is research (Valencia-Vallejo, López-Vargas, \& Sanabria-Rodríguez, 2018) that has studied the effects of motivational scaffolding on self-efficacy and learning achievement in students with 
different cognitive styles in the Field Dependence/Independence (FDI) dimension when interacting in a mathematics e-learning environment. This research had an experimental design with two groups and a post-test. One group of students interacted with an e-learning environment that contained motivational scaffolding, and the other group interacted with an e-learning environment without the scaffolding. The results showed significant differences in learning achievement and academic self-efficacy attributable to the effect of scaffolding. In addition, it was found that the interaction with the computational environment neutralized cognitive style effects. Another study (UNUGO, 2021) revealed that scaffolding teaching strategies improved students' achievement and recommended that teachers regularly use scaffolding to enhance the effectiveness of their instruction and improve the academic performance and achievement of students. Also, Kim, Vicentini, and Belland (2021) investigated the positive and negative effects of computer-based scaffolding to support high-school students' information literacy and argumentation skills in a problem-based learning unit on air quality. Virtual field trips and a 'connection log' were designed and developed to provide scaffolding that supported students in addressing conceptual, metacognitive, and strategic challenges. The results revealed that diverse students could use scaffolding in different ways based on distinct goals and prior experiences. These findings imply that information literacy and argumentation skills supported by computer-based scaffolding are pivotal factors in problem-based learning for science education.

Although new curricula, as well as new software tools described as scaffolds, have provided us with new techniques to support student learning, the important theoretical features of scaffolding, such as ongoing diagnosis and calibrated support, are being neglected (Puntambekar \& Hubscher, 2005). Sengupta, Mukherjee, and Bhattacharya propose using this scaffolding for synchronous interaction sessions between learners and instructors. This has the best results when it takes the form of tutorial sessions that supplement the students' self-regulated learning (Sengupta, Mukherjee, \& Bhattacharya, 2012). Finally, there are those who have emphasized that online instructors' use of scaffolding strategies to promote interactions demonstrates psychometrically sound validity and reliability (Cho \& Cho, 2016).

The researcher presently believes that the form of instruction emerges between teachers and students, mediated through technology, and that learning communities exist in online settings. Thus, it is important to acknowledge the suitable forms of support required by the students, especially in an online learning environment (Jumaat \& Tasir, 2014). We need to discuss how scaffolding can play a larger role in the work of all practitioners to enable students to expand their ability to think critically and participate in the discourse communities they aspire to join (Wilson \& Devereux, 2014). Intended learning outcomes for any educational content can be improved through strategic interventions and careful scaffolding. Scaffolding also aids the development of teachers' ability to effectively incorporate reflection into experience-based learning curricula in higher education (Coulson \& Harvey, 2013). Teachers in the majority of higher education institutions are of the opinion that scaffolding is a useful addition, and they have requested more time and support to implement newly learned strategies in daily practice (Kruiper, Leenknecht, \& Slof, 2021).

\section{Conclusions}

The researcher created a list of the learning design skills required for technology-enhanced learning students, which consisted of seven (7) basic skills, as follows: basic educational design skills, the basic skills of the stages of instructional design, skills of the analysis phase, skills of the design phase, skills of the development phase, skills of the application and final evaluation phase, and skills of the use and follow-up phase. Each skill is further divided into a set of sub-skills (40 in total). The researcher presented the list to four (4) arbitrators, made the required modifications, and finalized the list of skills. Based on the skills list, the researcher produced e-content to teach the necessary educational design skills to educational technology students using three levels of scaffolding (simple, intermediate, and intensive). Moodle was selected as the e-learning environment.

The results showed that the students in the third experimental group, who benefited from intensive scaffolding in educational design skills, outperformed the others. The complex scaffolding level offered the content richest in examples and questions, as well as the type of expert organization that provided a ready model for each stage of instructional design, containing all the steps and skills. The results further showed that neither the students in the first group, who studied e-content with simple educational scaffolding, nor those in the second group, who studied e-content with intermediate educational scaffolding, reached a degree of proficiency with the material that could be labeled mastery. In contrast, the students in the third group, who studied e-content with complex educational scaffolding, attained mastery of the subject, although this was not at the level of statistical significance.

Since the completion of the research experiment, and based on the results of the research paper, the researcher can confirm that the design of e-content during the years 2017-2021 includes complex educational scaffolding, full of examples and questions and organized based on the concept of the expert model, which had a significant impact in clarifying many complex skills for students. The National E-Learning Center (NELC) and all the sub-production centers in Egyptian universities focus on producing electronic content based on complex scaffolding.

\section{References}

Abdel Kafi, I. (2009). The effect of using some aspects of learning scaffolding in multimedia computer programs on achievement and developing metacognitive skills among educational technology students. Master's Thesis, Faculty of Specific Education, Tanta University, Egypt. Available from Federation of Egyptian University Libraries database. (MT No. 24109).

Afifi, M. K. (2010). Scaffolding as an approach for designing and developing e-curricula and its effectiveness on the students' performance in project-based learning and satisfaction with learning in E-environment. Journal of Arab Society for Educational Technology, 9(4), 63107.

Al- Ghareeb, Z. I. (2009). E-contents: Design, production, publication, application, and assessments. Cairo: Alam elKutub.

Al- Muteiry, S. H. (2008). The impact of technology approach on E-training for the development of some E-curricula at pedagogic faculty staff at Saudi Arabia and their attitudes towards it. Unpublished Ph.D. Dissertation. Educational Studies Institute.

Al-Salami, Z. (2008). The effect of interaction between two types of learning scaffolding and learning style when designing multimedia computer programs on achievement, learning time and self-learning skills among female student teachers. PhD Thesis, College of Girls, Ain Shams University, Egypt) Available from Federation of Egyptian University Libraries Database. (MT No. 2318).

Alvarez, C., \& Cuesta, L. (2012). Designing for online interaction: Scaffolded and collaborative interventions in a graduate-level blended course. Paper presented at the EUROCALL Review. Proceedings of the EUROCALL 2011 Conference. 
Azevedo, R., Cromely, J. G., Leslie, T., Seibert, D., \& Tron, M. (2003). Online process scaffolding and student's self-regulated learning with hypermedia. Paper presented at the American Educational Research Association (Chicago, Il, April 2003, 21-25). (ERIC Document Reproduction Service No. ED 478 069).

Block, J. H., \& Burns, R. B. (1976). Mastery learning. Review of Research in Education, 4(1), 3-49.

Chang, M. Y., Tarng, W., \& Shin, F. Y. (2009). The effectiveness of scaffolding in a web-based, adaptive learning system. International Journal of Web-Based Learning and Teaching Technologies, 4(1), 1-15.

Cho, M.-H., \& Cho, Y. (2016). Online instructors' use of scaffolding strategies to promote interactions: A scale development study. International Review of Research in Open and Distributed Learning: IRRODL, 17(6), 108-120.Available at: https://doi.org/10.19173/irrodl.v17i6.2816.

Coulson, D., \& Harvey, M. (2013). Scaffolding student reflection for experience-based learning: A framework. Teaching in Higher Education, 18(4), 401-413.Available at: https://doi.org/10.1080/13562517.2012.752726.

Dolaty, M. A. (2011). The impact of the different guidance levels in multi-media programs on developing math proof skills for secondary 1 st year. Ph.D. Educational Studies Institute. Cairo University.

Donovan, C. A., \& Smolkin, L. B. (2011). Supporting informational writing in the elementary grades. The Reading Teacher, 64(6), 406416.Available at: https://doi.org/10.1598/rt.64.6.2.

Gad, N., \& Al-Maradini, M. (2010). The effect of interaction between different types of constructivist learning pillars within the e-book on the achievement and learning efficiency of postgraduate students in the faculties of education. Journal of the Faculty of Education, 16(3), $251-321$.

Hou, H.-T., \& Keng, S.-H. (2021). A dual-scaffolding framework integrating peer-scaffolding and cognitive-scaffolding for an augmented reality-based educational board game: An analysis of learners' collective flow state and collaborative learning behavioral patterns. Journal of Educational Computing Research, 59(3), 547-573.Available at: https://doi.org/10.1 177/0735633120969409.

Jumaat, N. F., \& Tasir, Z. (2014). Instructional scaffolding in online learning environment: A meta-analysis. Paper presented at the 2014 International Conference on Teaching and Learning in Computing and Engineering. IEEE.

Khamis, M. A. (2015). E-learning sources. Part I: Individuals and Media (1st ed.). Cairo: Dar El Sahab for Publication and Distribution.

Kim, N. J., Belland, B. R., \& Axelrod, D. (2018). Scaffolding for optimal challenge in K-12 problem-based learning. The Interdisciplinary Journal of Problem-Based Learning, 13(1), 3.Available at: https://doi.org/10.7771/1541-5015.1712.

Kim, N. J., Vicentini, C. R., \& Belland, B. R. (2021). Influence of scaffolding on information literacy and argumentation skills in virtual field trips and problem-based learning for scientific problem solving. International Journal of Science and Mathematics Education, 20(2), 215236.Available at: https://doi.org/10.1007/s 10763-020-10145-y.

Kruiper, S. M., Leenknecht, M. J., \& Slof, B. (202 1). Using scaffolding strategies to improve formative assessment practice in higher education. Assessment \& Evaluation in Higher Education, 1-19.Available at: https://doi.org/10.1080/02602938.202 1.1927981.

Lajoie, S. P. (2005). Extending the scaffolding metaphor. Instructional Science, 33(5-6), 541-557.Available at: https://doi.org/10.1007/s11251005-1279-2

Oliver, R., \& Herrington, J. (2001). Teaching and learning online: A beginners guide to E-learning and E-teaching in higher education. Australia: Center for Research in Information Technology and Communications, Edith Crown University.

Puntambekar, S., \& Hubscher, R. (2005). Tools for scaffolding students in a complex learning environment: What have we gained and what have we missed? Educational Psychologist, 4O(1), 1-12.Available at: https://doi.org/10.1207/s15326985ep4001_1.

Resier, R. A. (2002). A history of instructional design and technology. Trends and Issues in Instructional Design, 26-53.

Riad, H. A. A. (2002). Mastery learning and the possibility of its application in our schools in the various stages of pre-university education considering the available possibilities and the presence of large numbers of students in the classroom. Journal of the National Center for Educational Research and Development in Egypt, 18(1), 33-71.

Schutt, M. (2003). Scaffolding for online learning environments: Instructional design strategies that provide online learner support. Educational Technology, 43(6), 28-35.

Sengupta, S., Mukherjee, B., \& Bhattacharya, S. (2012). Designing a scaffolding for supporting personalized synchronous e-learning. Kolkata-150, India: Department of Computer Science \& Information Technology, Bengal Institute of Technology.

Shahinaz, A. M. (2007). Effectiveness of using learning scaffolding in computer-based learning programs in developing E-writing skills for English teachers. Unpublished Ph.D. Dissertation. Faculty of Women, Ain Shams University.

Shapiro, A. M. (2008). Hypermedia design as learner scaffolding. Educational Technology Research and Development, 56(1), 29-44.Available at: https://doi.org/10.1007/s11423-007-9063-4.

Simons, K. D., \& Ertmer, P. (2006). Scaffolding disciplined inquiry in problem-based environments. International Journal of Learning, 12(6), 297-305.Available at: https://doi.org/10.18848/1447-9494/cgp/v12io6/47900.

Sofi, S. Y. (2006). The impact of the different guidance levels and styles of introducing it in multi-media programs on the cognitive and behavioral aspects of the students in mental disabilities schools. Unpublished Dissertation. Faculty of Women, Ain Shams University.

Stewart, T. M., MacIntyre, W. R., Galea, V. J., \& Steel, C. H. (2007). Enhancing problem-based learning designs with a single e-learning scaffolding tool: Two case studies using challenge FRAP. Interactive Learning Environments, 15(1), 77-91.

Tawfiq, M., \& Al-Heela, M. (1998). The uniqueness of education (1st ed.). Amman: Dar Al-Fikr for Publishing.

UNUGO, L. O. (202 1). Effects of scaffolding teaching strategy on the academic achievement of students in social studies for value reorientation and national development. UNIZIK Journal of Educational Research and Policy Studies, 6(1), 92-100.

Valencia-Vallejo, N., López-Vargas, O., \& Sanabria-Rodríguez, L. (2018). Effect of motivational scaffolding on E-learning environments: Selfefficacy, learning achievement, and cognitive style. Journal of Educators Online, 15(1), n1.Available at: https://doi.org/10.9743/jeo2018.15.1.5.

Wilson, K., \& Devereux, L. (2014). Scaffolding theory: High challenge, high support in academic language and learning (ALL) contexts. Journal of Academic Language and Learning, 8(3), A91-A 100.

Zydney, J. M. (2003). The effect of different types of scaffolding in a multimedia program on students' ability to define a complex problem. Paper presented at the Annual of the Eastern Educational Research Association. (Hilton head.sc. February 26- March 1, 2003). 